\title{
Lacunar versus non-lacunar infarcts: pathogenetic and prognostic differences
}

\author{
G Landi, E Cella, E Boccardi, M Musicco
}

\begin{abstract}
To characterise the pathogenetic and prognostic features of lacunar infarcts, 88 patients with these infarcts were compared with 103 patients with non-lacunar infarcts. Potential cardioembolic sources were significantly more frequent among patients with non-lacunar infarcts $(p=$ $0 \cdot 0025)$. Although the prevalence of hypertension was higher among lacunar infarcts, this difference was not statistically significant. However, the distribution of hypertensive patients in the two groups of lacunar and non-lacunar infarcts was influenced by the presence or absence of cardioembolic sources: hypertension was significantly associated with the presence of cardioembolic sources among non-lacunar infarcts, whereas among lacunar infarcts it was significantly more frequent in patients without a cardioembolic source. This indicates that cardioembolism may exert a confounding effect by suppressing the relation between hypertension and lacunar infarcts. In a mean follow up period of $28 \cdot 1$ months, lacunar infarcts had a significantly lower incidence of stroke recurrence and of myocardial infarction (age-adjusted survival analysis: $p=0.0008$ ); mortality from all causes was also lower in patients with lacunar infarct (age-adjusted survival analysis: $0.04<p<0.05)$. In a multivariate regression analysis, stroke subtype was an independent predictor of new major vascular events. These findings support the lacunar hypothesis and should be considered in the planning of epidemiological and therapeutic studies in patients with cerebral infarction.
\end{abstract}

Neurological Clinic, Ospedale Policlinico, Milan, Italy

G Landi E Cella

Department of Neuroradiology, Ospedale Niguarda, Milan, Italy

E Boccard

National Research

Council, Institute of

Advanced Biomedical

Technologies

Department of

Epidemiology, Milan,

Italy

M Musicco

Correspondence to: Dr Landi, Clinica

Neurologica, Ospedale

Policlinico, Via F Sforza 35, 20122 Milan, Italy.

Received 7 June 1991 and in revised form 7 August 1991. Accepted 5 September 1991 vactors and of several clinical and instrumental that cardiac and arterial embolism may also
Fisher's pathological studies related hypertension. ${ }^{12}$ Lacunar infarcts were the possibility of distinguishing a sub pasis of their hypothesis employed CT to recognise infarcts with other groups of ischaemic strokes by analysing the distribution of vascular risk give rise to lacunar infarcts, and since hypertension was absent in a substantial proportion of cases, the lacunar hypothesis has recently been questioned. ${ }^{8}$ Although there is general agreement on the favourable short-term prognosis of lacunar infarcts, ${ }^{9}$ only a few studies have reported on their long-term outcome, with contradictory conclusions. ${ }^{1011}$

As lacunar infarcts represent almost $25 \%$ of all ischaemic strokes ${ }^{11}$ and an even higher proportion of stroke survivors, further characterisation of their pathogenetic and prognostic features appears of more than academic interest and may contribute to the design of therapeutic studies after acute stroke. We therefore compared a group of patients with lacunar infarct to another group with nonlacunar ischaemic stroke.

\section{Patients and methods}

The detailed method of our study has been described. ${ }^{12}$ In brief, we included prospectively 191 consecutive patients with first-ever ischaemic stroke visited at the emergency room of the Policlinico Hospital in Milan within 72 hours after the onset of symptoms and hospitalised at the local neurological department. All patients had a neurological and general physical examination on arrival at the emergency room; this was repeated daily during the first week and twice weekly until discharge, enabling us to subdivide them into two groups according to their neurological state at the time of maximum deficit.

Lacunar infarct $(\mathrm{LI})(\mathrm{n}=88)$, was defined as one of the following syndromes: pure motor stroke (unilateral pure motor deficit involving at least two of three areas - face, arm and leg); pure sensory stroke (unilateral pure sensory deficit involving at least two of three areasface, arm and leg); ataxic hemiparesis (ipsilateral corticospinal and cerebellar-like dysfunction without other features clearly localising to the posterior circulation); dysarthria-clumsy hand syndrome (severe dysarthria with slight weakness and clumsiness of the hand); and hemichorea/hemiballism (involuntary arrhythmic unilateral movements involving at least two of three areas-face, arm and leg). At the time of our study the inclusion of sensorimotor strokes among the lacunar syndromes was still debatable, and these patients were therefore not included in this report. $^{12}$

Non-lacunar infarcts (NLI) $(n=103)$ included all patients whose clinical picture did not conform to the preceding clinical syn- 


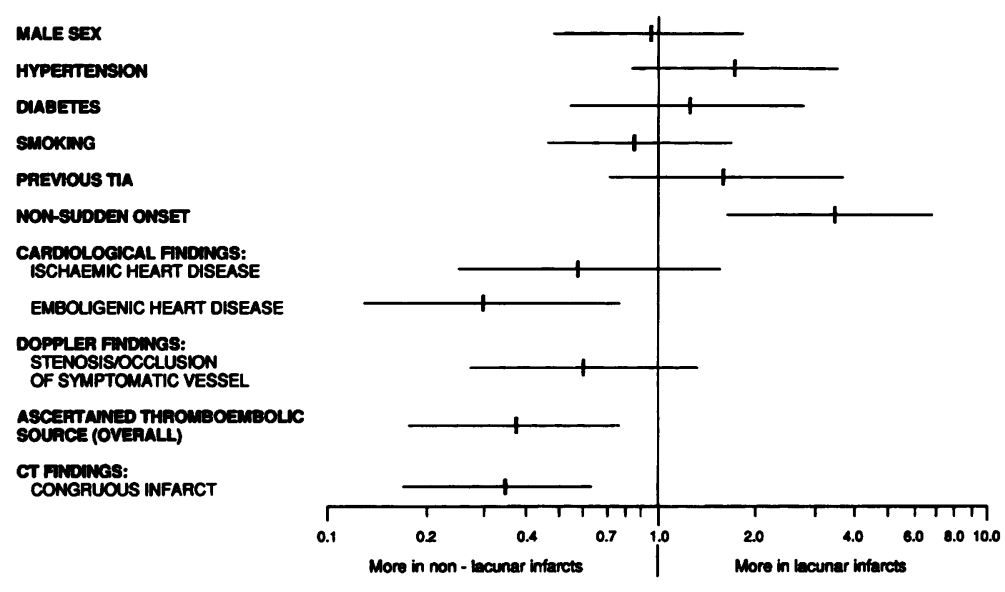

ODDS RATIO $(95 \% \mathrm{Cl})$

Figure 1 Comparison of the prevalence of risk factors, clinical and instrumental findings in lacunar and non-lacunar infarcts, showing the odds ratios (OR, vertical bars) and the 95\% CI (horizontal bars) on a logarithmic scale. An OR > 1.0 indicates higher prevalence among lacunar infarcts (LI), and an $O R<1.0$ a higher prevalence among non-lacunar infarcts (NLI).
Table 1 Age, sex and cerebrovascular risk factors according to stroke subtype

\begin{tabular}{|c|c|c|}
\hline & $\begin{array}{l}\text { Lacunar } \\
\text { infarcts } \\
n=88\end{array}$ & $\begin{array}{l}\text { Non-lacunar } \\
\text { infarcts } \\
n=103\end{array}$ \\
\hline $\begin{array}{l}\text { Age* } \\
\text { Male sex } \\
\text { Hypertension } \\
\text { Diabetes } \\
\text { Smoking } \\
\text { Previous TIA } \\
\text { Cholesterol }(\mathrm{mg} / \mathrm{dl})^{\star} \\
\text { Triglycerides }(\mathrm{mg} / \mathrm{dl})^{\star}\end{array}$ & $\begin{array}{r}63 \cdot 5(12 \cdot 5) \\
55(62 \cdot 5 \%) \\
57(64 \cdot 8 \%) \\
17(19 \cdot 3 \%) \\
36(40 \cdot 9 \%) \\
20(22 \cdot 7 \%) \\
227 \cdot 7(41 \cdot 7) \\
153 \cdot 2(96 \cdot 6)\end{array}$ & $\begin{array}{r}66 \cdot 1(12 \cdot 4) \\
63(61 \cdot 2 \%) \\
54(52 \cdot 4 \%) \\
17(16.5 \%) \\
46(44 \cdot 7 \%) \\
16(15 \cdot 5 \%) \\
223.0(57 \cdot 5) \\
135.9(60.0)\end{array}$ \\
\hline
\end{tabular}

were recorded, and residual disability in survivors was established at one month and classified as follows: Not disabled-independent in self-care, with return to pre-stroke activities; Partially disabled-requiring help in activities of daily living, able to walk with or without assistance; Severely disabled-bedridden or confined to a wheel chair, requiring constant care.

All patients who survived their first-ever stroke were followed for at least 12 months or until death, and occurrence of new cerebrovascular events was reported. Stroke recurrence was classified as: mild if there was no or only slight persistent deterioration with respect to previous neurological deficit; severe if deterioration was significant; or fatal. Occurrence of myocardial infarction and of death from other causes were also recorded.

\section{Statistical methods}

The strength of association between the considered variables and the type of stroke (LI or NLI) was calculated by means of odds ratio $(\mathrm{OR})^{14}$ and their statistical significance was evaluated by chi-square. Confidence intervals of OR were calculated as suggested by Cornfield. ${ }^{15}$ The significance of the difference between means was tested with two-tailed $t$ tests for unpaired data. Survival analyses on the cumulative time dependent probability of major vascular events (stroke, myocardial infarction) and of death were carried out by the Kaplan-Meier method and the strength of the association of these probabilities with possible prognostic variables was evaluated by hazard ratio (HR). ${ }^{16}$ Cox's model was employed to carry out multivariate regression analysis. ${ }^{17}$ in seven patients with NLI $(6.8 \%)$ and in four with LI (4.5\%). Ischaemic heart disease was diagnosed if patients had a typical history of angina or acute myocardial infarction, or clear-cut ECG evidence of previous myocardial infarction. Emboligenic heart disease was diagnosed in the presence of atrial fibrillation, endocarditis, mitral valve disease, left ventricular aneurysm or thrombus. A continuous-wave doppler study of the extracranial vessels was performed ${ }^{13}$ in all patients except three (all with NLI), who died early after admission to hospital.

Sixty one patients considered for carotidendarterectomy had cerebral angiography by transfemoral catheterisation. Their angiographic picture was correlated with the results of ultrasonic examination.

Deaths occurring as a consequence of stroke
Table $2 C T$ results, cardiological findings and prevalence of thomboembolic sources

\begin{tabular}{|c|c|c|}
\hline & $\begin{array}{l}\text { Lacunar } \\
\text { infarcts } \\
n=88\end{array}$ & $\begin{array}{l}\text { Non-lacunar } \\
\text { infarcts } \\
n=103\end{array}$ \\
\hline $\begin{array}{l}\text { Positive CT scan (congruous } \\
\text { infarct) }\end{array}$ & $37(42 \cdot 0 \%)$ & $71(68 \cdot 9 \%)$ \\
\hline $\begin{array}{l}\text { Ischaemic heart disease } \\
\text { Emboligenic heart disease }\end{array}$ & $\begin{array}{l}10(11 \cdot 4 \%) \\
11(12.5 \%)\end{array}$ & $\begin{array}{l}19(18.4 \%) \\
33(32.0 \%)\end{array}$ \\
\hline $\begin{array}{l}\text { Stenosis/occlusion of } \\
\text { symptomatic vessel } \\
\text { (doppler) }\end{array}$ & $16(18 \cdot 2 \%)$ & $27^{\star}(27 \cdot 0 \%)$ \\
\hline $\begin{array}{l}\text { Total with ascertained } \\
\text { thromboembolic source }\end{array}$ & $27(30 \cdot 7 \%)$ & $56+(54 \cdot 4 \%)$ \\
\hline
\end{tabular}


Table 3 Distribution of hypertension among lacunar and non-lacunar infarcts according to presence or absence of cardioembolic sources

\begin{tabular}{|c|c|c|c|c|}
\hline & \multicolumn{2}{|c|}{ Absence of cardioembolic source } & \multicolumn{2}{|c|}{ Presence of cardioembolic source } \\
\hline & Hypertension + & Hypertension - & Hypertension + & Hypertension - \\
\hline \multirow{3}{*}{$\begin{array}{l}\text { Lacunar infarcts } \\
\text { Non-lacunar infarcts } \\
\text { Presence of hypertension } \\
\text { Presence of hypertension } \\
\text { source } \\
\text { Presence of cardioembol } \\
\text { Presence of cardioembol } \\
\text { hypertension }\end{array}$} & $\begin{array}{l}51 \\
34 \\
1 \text { in patients with } \\
\text { in patients with }\end{array}$ & $\begin{array}{l}26 \\
36 \\
\text { cardioembolic source } \\
\text { out cardioembolic }\end{array}$ & ${ }^{6}{ }^{6} \mathrm{OR} *(95 \%$ & $\begin{array}{l}5 \\
13 \\
C I): 0 \cdot 8(0 \cdot 2-3 \cdot 0)\end{array}$ \\
\hline & $\begin{array}{l}\text { ic source in patie } \\
\text { ic source in patie }\end{array}$ & & $\begin{array}{l}\mathrm{OR}^{\star}{ }^{*}(95 \%) \\
\mathrm{OR}\end{array}$ & $\begin{array}{l}\text { CI): } 2 \cdot 1(1 \cdot 1-4 \cdot 0) \\
C I): 0 \cdot 2(0 \cdot 1-0 \cdot 5)\end{array}$ \\
\hline & & & $O R *(95 \%$ & $C I): 0.5(0.2-1.7)$ \\
\hline
\end{tabular}

* Non-lacunar infarcts as reference category (an $O R>1.0$ indicates higher prevalence among lacunar infarcts, and an $O R<1.0$ a higher prevalence among non-lacunar infarcts)

\section{Results}

Out of our 88 patients with LI, 67 presented with a pure motor stroke, eight with ataxic hemiparesis, six with pure sensory stroke, five with dysarthria - clumsy hand syndrome, and two with hemichorea/hemiballism. Overall, their age- and sex-distribution was rather similar to those of NLI, as shown in table 1, which also reports the prevalence of cerebrovascular risk factors in the two groups. No significant difference was observed either for continuous variables (age: $\mathrm{t}=0.45, \mathrm{p}=0.65$; cholesterol: $\mathrm{t}=0.64, \mathrm{p}=0.52$; triglycerides: $\mathrm{t}=1.51, \mathrm{p}=0.13$ ) nor for dichotomous variables (figure 1), although the frequency of hypertension was higher among patients with LI $(p=0 \cdot 11)$. Of the 57 patients with LI diagnosed as hypertensive, $46(80 \cdot 7 \%)$ had known hypertension, while pre-stroke blood pressure levels were reported as normal in eight $(14.0 \%)$ and were unavailable in three $(5 \cdot 3 \%)$; for $\mathrm{NLI}$, the corresponding figures were respectively, $43(79.6 \%)$, seven $(13.0 \%)$, and four $(7 \cdot 4 \%)$. A non-sudden onset of symptoms with a gradual, stepwise or stuttering course up to a maximum deficit was observed in $36 \mathrm{LI}(40.9 \%)$ as opposed to only 18 NLI (17.5\%) ( $p=0.006$; figure 1$)$.

Results of cardiological and instrumental evaluations are reported in table 2. CT scan demonstrated a congruous infarct (that is, appropriate to the side of symptoms) in $42.0 \%$ of $\mathrm{LI}$ and in $68.9 \%$ of NLI ( $p=0.0003$; figure 1). All 37 patients with $L I$ and a positive CT scan showed evidence of a lacunar lesion. In contrast, of the 71 patients with NLI who had a congruous infarct visualised at CT scan, 64 had evidence of a cortical or large subcortical

Table 4 Short-and long-term outcome according to stroke subtype

\begin{tabular}{lll}
\hline & $\begin{array}{l}\text { Lacunar infarcts } \\
n=88\end{array}$ & $\begin{array}{l}\text { Non-lacunar infarcts } \\
n=103\end{array}$ \\
\hline At 1 month & $51(58 \cdot 0 ; 47 \cdot 0-68 \cdot 4)$ & $31(30 \cdot 1 ; 22 \cdot 1-41 \cdot 0)$ \\
Absent disability & $33(37 \cdot 5 ; 27 \cdot 4-48 \cdot 5)$ & $43(41 \cdot 7 ; 33 \cdot 1-53 \cdot 3)$ \\
Partial disability & $4(4 \cdot 5 ; 1 \cdot 3-11 \cdot 2)$ & $14(13 \cdot 6 ; 7 \cdot 9-22 \cdot 4)$ \\
Complete disability & $0(0 \cdot 0 ; 0 \cdot 0-4 \cdot 1)$ & $15(14 \cdot 6 ; 8 \cdot 7-23 \cdot 5)$ \\
Dead & & \\
Follow up results & $31 \cdot 1$ & $25 \cdot 1$ \\
Mean duration (months) & $7(8 \cdot 0 ; 3 \cdot 3-15 \cdot 7)$ & $3(3 \cdot 4 ; 0 \cdot 7-9 \cdot 6)$ \\
TIA & $12(13 \cdot 6 ; 7 \cdot 3-22 \cdot 6)$ & $20(22 \cdot 7 ; 14 \cdot 5-32 \cdot 9)$ \\
Stroke & 4 & 4 \\
$\quad$ mild & 3 & 5 \\
$\quad$ severe & 5 & 11 \\
Mytal & $5(4 \cdot 5 ; 1 \cdot 3-11 \cdot 2)$ \\
$\quad$ fatal & $0(0 \cdot 1) ; 0 \cdot 0-4 \cdot 1)$ & 2 \\
Non-vascular death & $3(3 \cdot 4 ; 0 \cdot 7-9 \cdot 6)$ & $8(9 \cdot 1 ; 4 \cdot 0-17 \cdot 1)$ \\
\hline
\end{tabular}

$\chi^{2}$ for trend $=24.73 ; \mathrm{p}<0.0001$.

Numbers in brackets are the proportions and their $95 \% \mathrm{CI}$
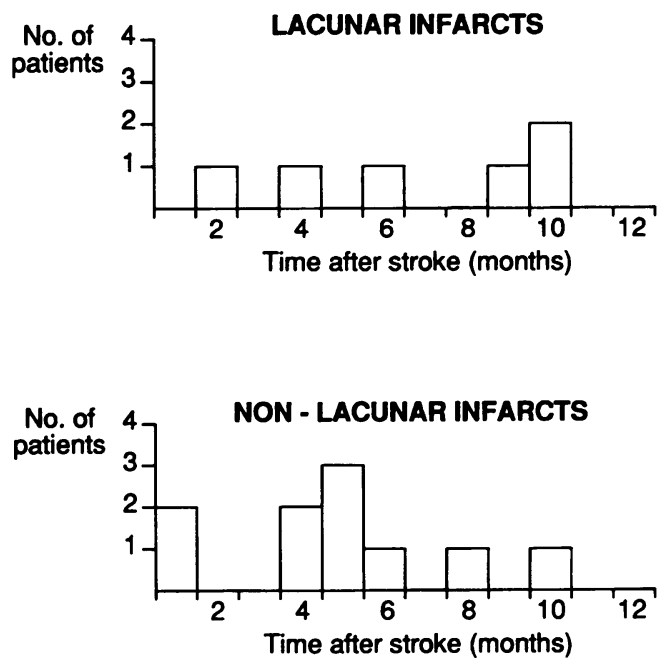

Figure 2 Interval to first recurrent stroke.

lesion, and only seven had evidence of a lacune. With the cardiological findings, no important difference was found in the prevalence of ischaemic heart disease, but atrial fibrillation and other emboligenic heart diseases were significantly more frequent among NLI $(p=0.0025$; figure 1$)$. Occlusion or stenosis of the symptomatic arterial district was demonstrated by angiography in 10 of 19 patients with NLI and in 10 of $42 \mathrm{LI}$. However, since angiography was performed only in a selected group of patients, we assessed the prevalence of vascular lesions by means of a Doppler ultrasound examination, which was available in $98.4 \%$ of our population, and whose sensitivity and specificity in diagnosing stenosis $>50 \%$ of the carotid and vertebral arteries was higher than $95 \%$ when compared with subsequent angiographic results. Although the higher frequency of obstructive lesions of the symptomatic arterial district among NLI compared with LI did not reach statistical significance $(p=0 \cdot 21)$, overall $54.4 \%$ of NLI had pathological Doppler results, emboligenic heart disease or both. The prevalence of such potential thromboembolic sources was significantly lower among LI ( $p=$ 0.002 ) (figure 1 ).

As the prevalence of emboligenic heart disease was significantly higher among NLI, we examined the relation between this variable and hypertension in our two groups. As shown in table 3, the distribution of hypertensive patients in our two groups of LI and NLI was influenced by the presence or absence of emboligenic heart disease: among patients without emboligenic heart disease hypertension was significantly more frequent in LI $(0.04<p<0.05)$, whereas no such relation was apparent among patients with emboligenic heart disease. Accordingly, among hypertensive patients, cardioembolic sources were more frequent in the group with NLI $(p=0.002)$, whereas no significant difference was observed in non-hypertensive patients.

Short-term prognosis was significantly better for LI than for NLI both in terms of mortality as a direct consequence of stroke, 


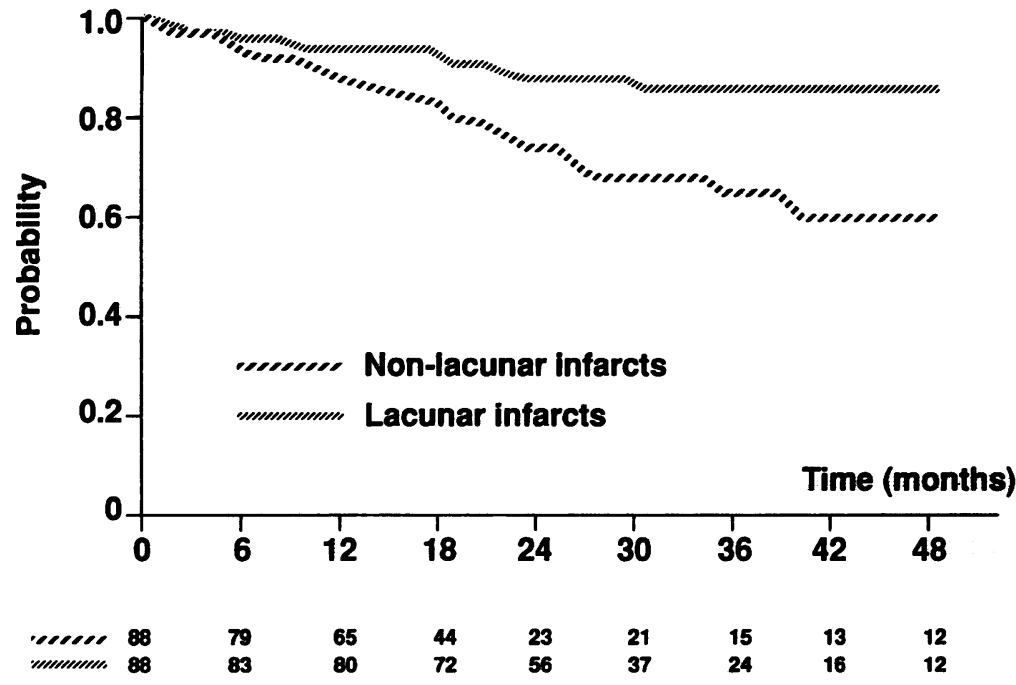

Figure 3 Cumulative probability of survival free from stroke and myocardial infarction according to stroke subtype. Follow up times of patients who died from causes other than stroke and myocardial infarction were censored at the time of death. Numbers are those of patients at risk at the beginning of each time interval.

and in terms of residual disability at one month (table 4). Among survivors, the cumulative one year probability of stroke recurrence was $7.9 \%$ for $\mathrm{LI}$ and $11.4 \%$ for NLI (OR $=0.67 ; p=0.6)$ The timing of these recurrences is shown in figure 2. Overall, in a mean period of $28 \cdot 1$ months, new vascular events occurred in $30.7 \%$ of NLI and in $21.6 \%$ of LI (table 4 ). This difference was even more remarkable if end-points were limited only to major vascular events (stroke, myocardial infarction), as their incidence among NLI (27.3\%) was more than twice with respect to LI (13.6\%). Survival analysis for major vascular events confirmed the strikingly better long-term outcome of $\mathrm{LI}$ ( $\mathrm{HR}=2 \cdot 7,95 \% \mathrm{CI} 1 \cdot 4-5 \cdot 2 ; \mathrm{p}=0.004$ ) (figure 3 ), which became even more evident when adjusting for age $(\mathrm{HR}=3.0,95 \% \mathrm{CI} 1 \cdot 6-5 \cdot 6$; $\mathrm{p}=0.0008$ ).

When only stroke recurrence is considered, HR was $2 \cdot 2$ (95\% CI $1 \cdot 1-6 \cdot 6 ; p=0.027)$ and age-adjusted $\mathrm{HR}$ was $2 \cdot 4(95 \% \mathrm{CI} 1 \cdot 2-4 \cdot 8 ; \mathrm{p}=$ $0 \cdot 01$ ). Results of a multivariate regression analysis including all tested variables demonstrated that the stroke subtype (that is, LI or NLI ) represented-together with age, occurrence of previous TIA, and residual disability at one month-an independent prognostic factor for the subsequent occurrence of major vascular events (table 5).

Table 5 Variables associated with major vascular events (stroke, myocardial infarction) in multivariate regression analysis

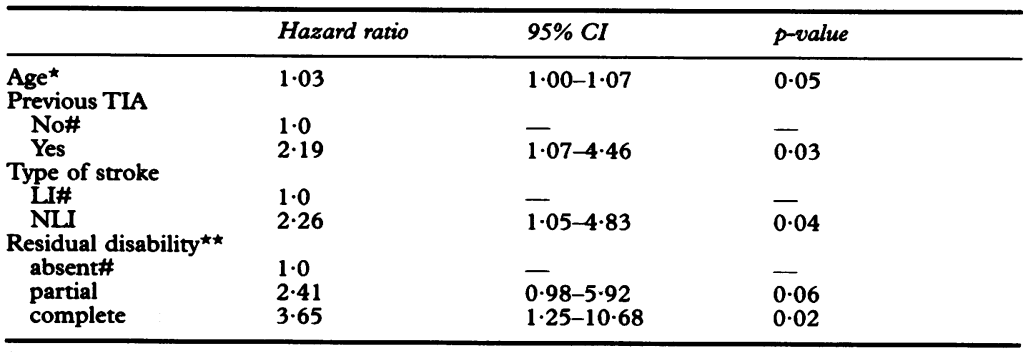

* Continuous variable.

\# reference category.

\section{Discussion}

To test the lacunar hypothesis we compared a group of patients with LI to another group with NLI. Unlike several previous studies, ${ }^{91819}$ we did not try to subdivide the latter strokes according to their pathogenesis into cardioembolic and atherothrombotic, since this distinction is often difficult or even impossible, and despite extensive investigations up to $40 \%$ of cerebral infarcts may remain of undetermined cause. ${ }^{20}$ We did not exclude patients with vertebrobasilar strokes because LI may also be located in the brainstem, and because there is no firm evidence that posterior circulation infarcts have a different pathogenesis and prognosis than carotid territory infarcts. Several authors have employed rigid criteria for the diagnosis of $\mathrm{LI}$, requiring absence of haemodynamic or embolic sources ${ }^{21}$ or even normal angiographic findings; ${ }^{18}$ however, these conditions may be difficult to fulfil, particularly on a large-scale basis, since they would require performance of extensive and often unnecessary instrumental investigations. In our study we relied on clinical examination for the diagnosis of LI, a simple method which can be easily applied in all settings. However, we included only patients with first-ever stroke, since residual signs of a previous insult may prevent correct diagnosis of a lacunar syndrome. Moreover, since our study was hospital-based, we were able to include patients with acute stroke $(91 \%$ of them were visited within 24 hours of onset) and to diagnose a lacunar syndrome when they had reached their maximum neurological deficit, as determined by repeated examinations, thus avoiding misdiagnosis in patients whose lacunar syndrome may just represent the outcome of a previously more extended clinical deficit.

Adherence to these criteria may explain why none of our patients with a lacunar syndrome had a non-lacunar lesion visualised at CT scan. Conversely, $6.8 \%$ of those with NLI had an appropriate lacunar lesion; although in a recent necropsy study $20 \%$ of symptomatic lacunes had presented with aphasia in addition to right hemiparesis, ${ }^{22}$ such lesions may well represent casual findings, since we observed lacunes also in the asymptomatic hemisphere of $11(10.7 \%)$ patients with NLI.

The $12.5 \%$ prevalence of potential cardiac sources of embolism among our LI agrees with previous reports; ${ }^{2324}$ it was significantly lower than among NLI, which again agrees with other series. ${ }^{2526}$ Indirect support to the conclusion that embolism occurred more often among NLI is provided by the significantly higher frequency of an abrupt onset of stroke in this group, as this feature has been positively associated with cardiogenic brain embolism. ${ }^{2728}$

Although lacunar strokes are commonly attributed to hypertensive arteriolopathy, the prevalence of hypertension among LI was not significantly higher in our study as in previous studies, ${ }^{182429}$ even if different diagnostic criteria for hypertension were considered. ${ }^{25}$ These studies concluded that "hypertension is no more important in the development of LI 
than it is in the development of other types of stroke", and a recent review drew the same conclusions. ${ }^{8}$ However, previous studies did not take into account potential confounding variables; this effect should be considered if such variables are dishomogeneously distributed between the groups. Of our LI, without cardioembolic sources, $66.2 \%$ were hypertensive as opposed to only $48.6 \%$ of NLI; this statistically significant difference was not observed in patients with cardioembolic sources. This, combined with the significant association between hypertension and cardioembolic sources among NLI, leads to the conclusion that cardioembolism may exert a confounding effect by suppressing the actual relationship between hypertension and LI.

The long-term prognosis of $\mathrm{LI}$ has received little attention. One study ${ }^{10}$ concluded that their average recurrence rate was "much lower than that in survivors from cerebral infarction". Another study ${ }^{11}$ found a one year recurrence rate of $11.9 \%(95 \% \mathrm{CI}$, $5 \cdot 5 \%-18 \cdot 0 \%$ ), "similar to that reported in other groups of patients with stroke". Both these contradictory conclusions were based on a comparison with historical controls. By directly comparing our patients with $\mathrm{LI}$ with a group of NLI, we found that the occurrence of new major vascular events was significantly lower in LI than in NLI. This agrees with the results of a recent study ${ }^{30}$ reporting a lower one year stroke recurrence rate among LI than for other types of cerebral infarction. The authors further interpreted the distinct low even recurrence rate among $\mathrm{LI}$ as compatible with the hypothesis that for a further stroke to develop another perforating artery needs to become symptomatic. Although the recurrence pattern among our patients with $\mathrm{LI}$ was similar to that study, we did not observe a similarly high recurrence rate among our cases with NLI, whose survival curve maintained a fairly constant slope even after the first year. The worse long-term prognosis of NLI in our study was reflected also by their higher overall mortality (age-adjusted survival analysis: $\mathrm{HR}=2 \cdot 0,95 \%$ CI 1.0-4.0;0.04 < p < 0.05).

Moreover, in multivariate regression analysis, stroke subtype was a predictor of new major vascular events, independent from other prognostic variables including degree of disability after the first stroke. This indicates that the probability of new major vascular events is related not only to severity of the first stroke, but alsu to its pathogenetic mechanisms. Despite the fact that in a clinical setting adequate investigation is appropriate to recognise the minority of patients in whom $\mathrm{LI}$ is caused by thromboembolism, the pathogenetic and prognostic peculiarities of this subgroup of ischaemic strokes should be considered in the planning of epidemiological and therapeutic studies after cerebral infarction.

1 Fisher CM. Lacunes: small, deep cerebral infarcts. Neurology 1965;15:774-84.

Fisher CM. The arterial lesions underlying lacunes. Acta Neuropath 1969;12:1-15.

Fisher CM. Pure motor hemiplegia of vascular origin. Arch Neurol 1965;13:30-44.

4 Fisher CM. Lacunar strokes and infarcts: a review. Neurology 1982;32:871-6.

5 Nelson RF, Pullicino P, Kendall BE, Marshall J. Computed tomography in patients presenting with lacunar syndromes. Stroke 1980;11:256-61.

6 Donnan GA, Tress BM, Bladin PF. A prospective study of lacunar infarction using computerized tomography. Neurology 1982;32:49-56.

7 Arboix A, Marti-Vilalta JL, Garcia JH. Clinical study of 227 patients with lacunar infarcts. Stroke 1990;21:842-7.

8 Millikan C, Futrell N. The fallacy of the lacune hypothesis. Stroke 1990;21:1251-7.

9 Foulkes MA, Wolf PA, Price TR, Mohr JP, Heir DB. The Stroke Data Bank: Design, methods, and baseline characteristics. Stroke 1988;19:547-54.

10 Gandolfo C, Moretti C, Dall'Agata D, Primavera A, Brusa $\mathrm{G}$, Loeb C. Long-term prognosis of patients with lacunar syndromes. Acta Neurol Scand 1986;74:224-9.

11 Bamford JM, Sandercock P, Jones L, Warlow C. The natural history of lacunar infarction: The Oxfordshire community stroke project. Stroke 1987;18:547-51.

12 Landi G, Anzalone N, Cella E, Boccardi E, Musicco M. Are sensorimotor strokes lacunar strokes? A case-control sensorimotor strokes lacunar strokes? A case-control study with lacunar and non-lacunar
Neurosurg Psychiatry 1991;54:1063-8.

13 Budingen HJ, von Reutern GM, Freund HJ. DopplerSonographie der extrakraniellen Hirnarterien. Stuttgart: Georg Thieme 1982 .

14 Mantel M, Haenszel W. Statistical aspects of the analysis of data from retrospective studies of disease. $\mathcal{Y}$ Natl Cancer Inst 1959;22:719-48.

15 Cornfield J. A statistical problem arising from retrospective studies. In: Neyman J, ed. Proc 3rd Berkeley symposium, IV. Berkeley, CA: Berkeley University of California press, 1956:133-48.

16 Kaplan EL, Meier P. Non-parametric estimation from incomplete observations. F Am Stat Assac 1958;53: 457-81.

17 Cox DR. Regression model and life-tables. $\mathcal{f} R$ Statist Soc $B$ 1972;34:187-220

18 Mohr JP, Caplan LR, Melski JW, et al. The Harvard cooperative stroke registry: a prospective registry. Neurology 1978;28:754-62.

19 Bogousslavsky J, Van Melle G, Regli F. The Lausanne stroke registry: analysis of 1000 consecutive patients with first stroke. Stroke 1988;19:1083-92.

20 Sacco RL, Ellenberg JH, Mohr JP, et al. Infarcts of undetermined cause: The NINCDS Stroke Data Bank. Ann Neurol 1989;25:382-90.

21 Chamorro A, Sacco RL, Mohr JP, et al. Clinical-computed tomographic correlations of lacunar infarction in the Stroke Data Bank. Stroke 1991;22:175-81.

22 Tuszynski MH, Petito CK, Levy DE. Risk factors and clinical manifestations of pathologically verified lacunar infarctions. Stroke 1989;20:990-9.

23 Loeb C, Gandolfo C, Mancardi GL, Primavera A, Tassinari T. The lacunar syndromes: A review with personal T. The lacunar syndromes: A review with personal contribution. In: Lechner $\mathrm{H}$, Meyer JS, Ott E, eds. Cerebrovascular disease: research and clinical
Vol 1. Amsterdam: Elsevier, 1986:107-56.

24 Kappelle LJ, van Gijn J. Lacunar infarcts. Clin Neurol Neurosurg 1986;88:3-17.

25 Lodder J, Bamford JM, Sandercock PAG, Jones LN, Warlow CP. Are hypertension or cardiac embolism likely causes of lacunar infarction? Stroke 1990;21:375-81.

26 van Merwijk G, Lodder J, Bamford J, Kester ADM. How often is non-valvular atrial fibrillation the cause of brain infarction? $₹$ Neurol 1990;237:205-7.

27 Caplan LR, Hier DB, D'Cruz I. Cerebral embolism in the Michael Reese stroke registry. Stroke 1983;14:530-6.

28 Kittner SJ, Sharkness CM, Price TR, et al. Infarcts with a cardiac source of embolism in the NINCDS Stroke Data cardiac source of embolism in the NINCDS Stroke

29 van Gijn J, Kraaijeveld CL. Blood pressure does not predict lacunar infarction. $\boldsymbol{f}$ Neurol Neurosurg Psychiatry $1982 ; 45: 147-50$.

30 Bamford J, Sandercock P, Dennis M, Burn J, Warlow C. Classification and natural history of clinically identifiable subtypes of cerebral infarction. Lancet 1991;337: $1521-6$. 